CAQDAS: A Supplementary Tool for Qualitative Market Research

Ruth Rettie,

Senior Lecturer,

Kingston University,

Kingston Hill,

Surrey, KT2 7LB.

UK

Rm.Rettie@kingston.ac.uk

Helen Robinson

Principal Lecturer,

Kingston University,

Kingston Hill,

Surrey, KT2 7LB.

UK

Anja Radke,

Kingston University,

Kingston Hill,

Surrey, KT2 7LB.

UK

Xiajiao Ye,

c/o Kingston University,

Kingston Hill,

Surrey, KT2 7LB.

UK 


\section{CAQDAS: A Supplementary Tool for Qualitative Market Research}

Purpose

1) To assess the usage of CAQDAS (Computer Assisted Qualitative Data AnalysiS) in the UK market research industry, and 2) To evaluate the use of CAQDAS as a supplement to paper-coding in market research.

\section{Design/methodology/approach}

CAQDAS usage was assessed by a questionnaire, sent to a sample of 400 UK market researchers. The second part of the research is a case study of a research experiment. We conducted focus group research into online grocery shopping, supplementing a paper-coding based analysis with a further analysis based on computer coding.

\section{Findings}

Usage of CAQDAS in commercial market research is very low at only $9 \%$. Our research suggests that CAQDAS can be a useful supplement to traditional methods. Using computer software we were able to 1 ) mine the data for more detail; 2) clearly identify minority views; 3 ) and produce a useful resource for future research.

\section{Research limitations/implications}

The survey response rate was $38 \%$, but only 13 respondents used CAQDAS. Generalisation from a single experiment is problematic; our findings are affected by the research topic, research brief and the two research analysts.

\section{Practical implications}

The study has important implications for commercial qualitative market research. Repositioning CAQDAS as supplementary, rather than as an alternative, circumvents arguments about time pressure, and highlights its data management role.

\section{Originality/value}

This is the first large scale survey of qualitative research analysis in the UK market research industry. The case study describes an approach to CAQDAS that is innovative and relevant to commercial market research.

\section{Keywords}

Qualitative research analysis, commercial market research, CAQDAS, Qualrus, online grocery shopping

\section{Paper Type}

Research paper

\section{Introduction}

CAQDAS, or Computer Assisted Qualitative Data AnalysiS has been used in social research since the early '80s (Seidel and Clark, 1984). Becker, Gordon, and LeBailly (1984, p. 32) claimed in 1984 that "we have reached the stage of hardware and software development where a well-conceived computer assisted strategy can expedite and enhance each step of the qualitative research process". 
However, in market research CAQDAS is rarely used (Nancarrow, Moskin, and Shankar, 1996). This paper, firstly, reports a quantitative survey that measured the usage of CAQDAS among UK Market Research companies, and secondly, reports an experiment in which we evaluated the additional contribution of a supplementary CAQDAS based analysis, in an exploratory study of online grocery shopping.

\section{Background}

Huberman and Miles (1994) divide data analysis into three stages: data reduction, data display; conclusions and verification. Codes may be involved in all three stages. Coffey and Atkinson (1996, p. 27) stress that although coding may be part of the analysis process, it should not be thought of as a substitute for analysis. Coding links data fragments to concepts, but "the important analytic work lies in establishing and thinking about such linkages, not in the mundane processes of coding". However, Tesch (quoted by Thompson, 2002, sect. 4) contends that the coding process does not "merely consist of a random division into smaller units", but requires "skilled perception and artful transformation". Coding is "a theorizing process" (Richards and Richards, quoted by Bong, 2002). Different analysts may use different coding systems for the same data, and the same analyst may apply different coding systems at different stages; there is no one ideal coding structure. The process of analysis and coding is iterative, because the identification of relevant concepts and codes depends on analysis, but in analysis, codes are used as tools to "think with" (Coffey and Atkinson, 1996, p. 32). 
There is a substantial literature on the advantages of CAQDAS. In particular it can facilitate: data reduction; systematic coding; effective searching; the analysis of large data sets; the testing of hypotheses; and the identification of negative cases (Gerson, 1984; Padilla, 1991; Fielding, 1994; Coffey, Holbrook, and Atkinson, 1996; Catterall and Maclaran, 1998; Mason, 1999; Gordon, 1999; Ereaut, 2002). Conrad and Shulamit (1984) claim that using a computer for the more mechanical aspects of the process allows the researcher to devote more energy to analytic and interpretive work.

However, some (e.g. Bong, 2002) contend that CAQDAS encourages a focus on de-contextualised segments, and may misconstrue the nuances of language and meaning. Similarly, Catterall and Maclaran (1997) claim using computers for the analysis of focus groups may emphasise content at the expense of process. Roberts and Wilson (2002) claim that the ease and flexibility of software assisted coding may encourage the creation of too many codes and consequent loss of understanding of the overall picture. Coffey et al. (1996) and Lonkila (1995), argue that there is a risk that analysts may confuse coding with analysis, and neglect interpretation, and further, that CAQDAS creates a bias towards grounded theory but Lee and Fielding (1996) disagree, arguing that CAQDAS is adaptable for different analytic strategies. Writing in 1995, Pike and Thompson (Para. 73) envisage a time when CAQDAS analysis could be standard commercial practice and caution against over reliance on numeric content analysis and substitution of software for "the experience, analytic intuition and creative flair of the researcher". They also express concern at the loss of non-verbal cues. However, as Barker and Nancarrow (1999) report, software such as Observer Videopro enables computer analysis of video data. 
Ereaut (2002) explores the slow up-take of CAQDAS software within the market research industry, and concludes that two key reasons are avoidance in principle, due to perceived conflict between computers and qualitative research, and a mismatch between the available CAQDAS packages and the needs of commercial market researchers. Catterall and Maclaran (1998) contend that the negative attitudes of market researchers towards qualitative data analysis software arise from a confusion of computer assisted data management with numerical content analysis. In Maclaran and Catterall, (2002) they develop their argument and suggest that the term "computer analysis" is misleading, because the role of the computer is primarily database management, enabling quick access to the data, rather providing the analysis. Thus the computer facilitates storing, indexing and retrieving of the data; this supports, rather than replaces, the researcher's process of analysis and interpretation. Catterall and Maclaran (1998) claim this can enable a more creative analysis, for example, making it easier to test out hypotheses and to compare different user perceptions. Barker and Nancarrow (1999) explore the use of CAQDAS to create what they call a "qualitative brand databank". This long term resource would, they suggest, facilitate new product development, enabling companies to analyse trends, compare brand values across countries, and educate new marketing staff. Several authors (Catterall and Maclarenm 1998; Barker and Nancarrow, 1999; Maclaran and Catterall, 2002) suggest that CAQDAS creates transparency in the analysis process, and that this is useful for training new researchers and team work.

Market research agencies tend to use either a "holistic, interpretive approach" (Gordon and Langmaid, 1988), where transcripts are coded as a whole, or a "cut and paste" process where segments of the data are separated and allocated to 
different codes (Coffey and Atkinson, 1996). Dolan and Ayland (2001) compared these two coding techniques with CAQDAS. In their project, the holistic approach identified themes not identified by the other two coding methods. Nevertheless, they claim that there is a role for CAQDAS, especially in large and long term projects. However, their comparison is somewhat problematic, because they used two researchers for the holistic approach and only one for each of the other two techniques.

CAQDAS packages are rarely used by market research companies (Ereaut, Imms, and Callingham, 2002). Nancarrow, Moskin and Moskar (1996) report a survey of $46 \mathrm{UK}$ market research companies: only one out of the 26 that responded used a CAQDAS program. In Ireland the pattern is similar; Bezborodova and Bennett (2004) sent questionnaires to 88 Irish market research companies. Of the 46 companies that responded, only 7 had ever used special computer software for the analysis of qualitative data. The authors suggest several different reasons for this: CAQDAS is thought to foster a "quantitative like" style of analysis; commercial time pressures; a slow learning curve for CAQDAS coding; and inadequacies in the software packages that are available.

\section{Research Agenda}

The objectives of our study were firstly, to find out the extent to which CAQDAS is used within the UK market research industry, and secondly, to explore the additional contribution that CAQDAS coding could make to the analysis of qualitative market research. The research methodology and findings of each part of the study are described separately.

\section{Method: CAQDAS Usage Survey}


CAQDAS usage was assessed by a questionnaire, sent to a sample of 400 UK market researchers. A questionnaire was designed to assess coding practices in commercial market research, and piloted with market research colleagues. The sample frame was the 2006 edition of the Research Buyer's Guide, which is published by the UK Market Research Society (this guide was chosen rather than that of the Association of Qualitative Researchers, because we wanted to include full service agencies.) The guide included 765 agencies, which listed qualitative research as an area of expertise; starting at a random point we selected every second entry until we had 400 companies. To increase response rate, the questionnaires were hand addressed to a contact named in the guide, were sent by first-class post, and included an introductory letter and a first-class stamped addressed return envelope.

Our survey was subject to a number of limitations. Firstly, each company was treated as a single unit of the sampling frame, and we only sent the questionnaire to one individual within each company. Consequently, individuals within larger companies had less chance of being included in the survey, and we may therefore have introduced a bias towards smaller companies. However, we tested for this effect and found no statistically significant difference between responses from larger and smaller companies. Secondly, although the overall response rate was reasonable, if not ideal, at $38 \%$, the number of CAQDAS users was too small for statistical analysis.

\section{Method: Case Study of CAQDAS as a Supplementary Tool}

In the second part of the research, we did not attempt a direct comparison between computer assisted coding and more conventional coding. The time pressures within the market research industry mean that it is often impractical to 
use computer coding and meet client deadlines. For example, it is not unusual to expect an outline debrief within a week of the research. We were interested in testing the contribution of a second, supplementary analysis based on the data access afforded by CAQDAS software. It is short-sighted to think of these coding practices as mutually exclusive, because researchers can combine several methods when coding and analysing data. Cognizant of typical client requirements for quick feedback; we envisaged and evaluated an analysis process involving an initial analysis by the group moderator, culminating in a preliminary debrief, followed by a supplementary analysis based on computer coding.

Four $1 \frac{1}{2}$ hour focus groups on Internet grocery shopping were conducted by an experienced moderator of commercial market research. All respondents had shopped for groceries on the Internet, were over 25 years old and lived in Greater London. The groups were recorded, but not videoed, and the tapes were transcribed by a professional audio-typist.

\section{Take in Figure 1}

The research protocol is shown in Figure 1. Firstly, the group moderator analysed the transcripts using traditional paper coding and a thematic approach, producing an outline report and presentation. The transcripts and tapes were then given to a second analyst, together with copies of the report produced by the first analyst (the moderator). The second analyst also attended the debrief presentation. The second analyst coded the research brief, the transcripts and the outline report using Qualrus software. Codes were either derived from the first analysis, from the literature, or emerged from the data. The second analyst also listened to all the tapes in order to check their accuracy and identify intonation for key excerpts. The second analyst then prepared a report highlighting the differences between her 
computer-coded analysis and that of the first analyst. Finally a draft of this paper comparing their analyses was sent to the first analyst for comment.

In this type of experiment the results may be biased by the skills of the analysts. The first analyst was an academic and commercial moderator with over 30 years experience, and the second analyst was an undergraduate who had no previous experience of qualitative research analysis. We chose Qualrus software and found it easy and fairly intuitive to learn. Two of us attended an introductory Qualrus workshop run by the CAQDAS Networking Project at the University of Surrey. The second analyst kept a diary of her progress. The diary shows that it took her six days to code the project, but this may reflect her inexperience. In fact Catteral and Maclaran (1998) suggest that CAQDAS reduces the time required for coding.

Our codes were derived from several sources, and we therefore chose code names that indicated their source. For instance, we prefixed all codes derived from the first analysis with G, facilitating comparison between the two analyses. Qualrus codes can be attached to text of varying size from one word to several paragraphs; these textual data sections are called 'segments'.

Using Qualrus we found that it was very easy to identify coded segments, clicking on the relevant code in the code menu brought up a window showing all the segments with that code. Figure 2 shows the Qualrus Interface for the code 'Lifestyle Change'. Selecting any segment quickly brings up the relevant transcript and shows the segment in context.

\section{Take in Figure 2}


Our case study methodology is subject to several limitations. We explored only one case, and our findings will have been influenced by the topic area, the interview process and the research analysts themselves.

\section{Findings: CAQDAS Usage Survey}

The survey response rate was $38 \%$, with 153 complete questionnaires returned. There was no evidence of a non-response bias related to company size. Respondents were asked to indicate the coding approach they "usually used" when analysing qualitative data, and were allowed to choose more than one alternative from a list. On average respondents selected 1.5 methods. The most popular approach was "write comments and notes on the transcripts", which was selected by $71 \%$ of respondents, with "cut and paste using a word processor" as the second most popular method, at $47 \%$. Only 13 respondents (9\%) "usually used" "special computer software for the analysis of qualitative data", (see Table I).

\section{Take in Table I}

The table shows that awareness of CAQDAS is quite high; only $25 \%$ of respondents had not heard of computer analysis software. Interestingly, $10 \%$ had tried but never used, suggesting that some people have an immediate unfavourable reaction to the software. Of the thirteen who used the software at all, seven said they used it only occasionally and only two used it every time. For the few who used CAQDAS, the main benefits (chosen from a list derived from the literature) were that it helps when handling a large volume of data, that it helps when handling complex data, that it makes the analysis more scientific and that it makes the analysis more systematic. 
Respondents were asked to indicate the software packages they had heard of, see Table II. The brand with the highest awareness was NUDIST at $34 \%$, although the current version of the software is called N6. The software that has superseded NUDIST is called NVivo; this was only recognised by $13 \%$ of respondents. Although XSight was not on the list of brands in the questionnaire it was added by 9 respondents. This software is designed specifically for commercial use; these results indicate that it is succeeding in building awareness within the UK market research industry.

\section{Take in Table II}

The main reasons for not using computer software were that it "distances the analyst from the data" (51\%), that "the mechanical nature of the coding discourages reflection" (49\%) and that it "leads to a superficial analysis of the data" $(47 \%)$. Time pressure in research projects was relevant for $27 \%$. In addition to selecting from the reasons listed in the questionnaire (which were derived from the literature) respondents could write in their own comments. Over a quarter of respondents wrote that the computer cannot take the place of the brain (or similar comment), with several adding comments such as "blunt instrument" or "hopeless". Respondents stressed that qualitative analysis is an art which relies on intuition and skill, and were also concerned at the loss of non-verbal elements.

Not surprisingly respondents' overall ratings for computer assisted software were low, with $24 \%$ of those who had heard of the software claiming that it was useful. However, it is noteworthy that about $20 \%$ of those who have never tried the software believed, nevertheless, that it was useful. Overall rating was related to company type, with respondents from companies whose major business was 
quantitative research being significantly (Anova, $\mathrm{p}=.001$ ) more likely to regard qualitative analysis software as useful.

\section{Findings: Case Study of CAQDAS as a Supplementary Tool}

Our evaluation of the additional contribution of the CAQDAS based analysis includes: findings which elaborate those in the first report, additional findings which were not in the original analysis and findings which conflict with the first analysis. In the last part of this section we report our attempt to reconcile these differences in consultation with the first analyst.

\section{More Detailed Findings}

The substantive finding from the focus groups was that the decision to start, or stop, buying groceries online is prompted by a lifestyle change, for example having a baby, getting a dog, etc. This is important because it indicates that the decision to shop online is frequently re-evaluated, creating targetable opportunities for conversion. Qualrus enabled us to explore this dimension in considerable detail, producing a list of relevant lifestyle changes, which we have subsequently used in the design of a questionnaire, for the next stage of this research project.

We were interested in the relationship between online and offline shopping and, specifically, the differences in the categories of products bought in these two channels. Using Qualrus we were quickly able to examine all segments mentioning products that were typically bought online and all segments that mentioned product categories that were not bought online. This enabled us to define the two product categories in more detail. 
The thoroughness of our analysis using Qualrus was also demonstrated in other areas. For instance, whereas the first analysis suggested that respondents multitask while ordering their groceries, the subsequent computer analysis found that this was polarised, with some respondents deliberately refraining from multitasking.

\section{Additional Findings}

While the report by the first analyst focused on lifestyle changes as a rationale for starting online shopping, Qualrus helped us to identify other reasons. This more detailed analysis of usage antecedents showed that placing a specific order often depended on buying enough to justify the delivery costs.

Although many of the additional findings identified from the Qualrus coding were mentioned by only a few respondents, they may nevertheless be worth pursuing. For example, there were several comments suggesting waiving the delivery fee. This is an important and actionable motivator for the adoption of online grocery shopping. Another five service improvement suggestions were identified in the Qualrus coding process that were not in the original report.

Brand switching behaviour was one of the objectives defined in the brief, but this was only briefly covered in the first analyst's report. The second analysis picked up the role of loyalty cards as a switching barrier, and two interesting incidences of brand switching. One respondent explained how substitution of an own brand for the requested brand led to a permanent switch, another related brand switching to the different visual presentation of brands online. These are minority views, but nevertheless of interest, because they show how online shopping can affect brand choice: 
On one occasion I can remember Chelsea buns and I think I was buying a brand make and they gave me Tesco's own and they were really nice. So I thought I'll always buy Chelsea buns Tesco's brand rather than sort of the Hovis or whatever they were.

(Female light)

I changed my beer drinking habits through online shopping, because we were just browsing and saw some really nice ales, which normally you just skip by them in the supermarket, you go to the deals and stuff, but I thought, we'll give that a go. That was November last year, and I've completely changed my drinking beer. It wasn't something I would normally look at, but it leapt out, and you could read a bit more, a bit about it, and in a shop you only read the labels, whereas you can have a decent description of what you're going to buy online.

(Male group)

One area not in the brief, but emerging from the research, was store diversification. This was only reported in the Qualrus analysis. This was particularly interesting in that it showed a high degree of awareness of online store diversification into areas such as DVDs, insurance etc.

\section{Conflicting Findings}

The first analysis suggested that the online store Ocado was a clear favourite, both in terms of image and usage. This conflicts with market share data which shows that at $66 \%$ (Verdict, 2004) Tesco has a clear majority of this market. However, the groups took place during a period when Ocado was advertising heavily.

Using the Qualrus database we were able to quickly extract the 90 segments that mentioned Tesco, and compare them directly with the 38 segments mentioning Ocado. We found from this analysis that half the sample were Tesco shoppers and concluded that Tesco had more negative comments, because it was used by more respondents and by the more frequent users. Ocado was seen as 
expensive, but was commended for its web site, and customer service. Tesco users were more likely to have experienced some service difficulty, possibly because of their more frequent use, but many were nevertheless enthusiastic about online grocery shopping.

The first analysis identified delivery problems as a key reason for abandoning online grocery shopping. The second analysis suggests that problems with orders are equally important. Finally, whereas the first analysis suggested that vegetables and fruit were not bought online, there are seven comments reporting buying these online.

\section{Consultation with the First Analyst}

A draft of this paper was sent to the moderator/first analyst. In response, she pointed out that the key finding of the research was the role of life style changes in starting or stopping online grocery shopping. She commented that this might have been missed if we had used Qualrus as an alternative, rather than as a supplement to her analysis, because the identification of overall patterns is facilitated by immersion in the tapes and transcripts. However, use of CAQDAS facilitates rather than precludes immersion in the data. Moreover, using it as a supplementary tool means that it can complement, rather than replace, more traditional methods of analysis. In fact we gave the tapes to the second analyst, and encouraged her to listen to them and note respondents' intonation.

The first analyst also claimed that some of the additional findings were in fact included in the debrief presentation, although they were not in the report or presentation slides. In line with typical marketing practice, where speed and costs are usually important, we had only asked for an outline rather than a full report. 
The first analyst pointed out that if we had asked for a full report we would have received fuller details. On the discrepancy between on Tesco and Ocado, she commented that although more people used Tesco, "Ocado made people happier among the smaller sample of people who had used them". This is confirmed by the data, but this was not the general impression created by the debrief presentation. This illustrates how presentations are also interactional events and, as such, subject to different interpretations. This highlights the danger of recent trends in commercial market research away from written reports and increases the role of a computer database that can be accessed over time.

\section{Discussion and Conclusions}

Our survey of CAQDAS usage clearly indicates that, despite considerable awareness, there is minimal usage of computer assisted coding within the UK market research industry. This is surprising, given the use of CAQDAS among academic researchers and particularly sociologists (Ereaut, 2002) and given the availability of software such as XSight, which is specially designed for commercial research with tight deadlines. Nearly half the respondents were using a cut and paste word processor method, this suggests that many analysts are computer literate, who may be amenable to computer software. Our survey suggests that main problem is not time pressure, but a perception that CAQDAS distances the researcher from the data, leading to a mechanical, superficial analysis. However, CAQDAS is a coding process that facilitates data access rather than a method of analysis; CAQDAS coding does not preclude substantial, intuitive analysis (Fielding and Lee, 1998). Market research practitioners seem to assume that qualitative analysis software is a cut and paste technology that 
removes the data from its context; in fact, with most of these programmes a coded segment can be instantly seen within the context of the whole interview. Mason (1999) emphasises the importance of both cross and within case analysis. Comments about immersion and about reading the transcripts as a whole suggest that CAQDAS is seen as decontextualising the data. However, CAQDAS can be used to support a holistic approach, for example identifying order effects and inconsistencies within interviews.

There seems to be an assumption that computer aided analysis precludes more traditional forms of analysis, but the two approaches are often combined. For example, a researcher may print out all the segments under a particular code for a further manual coding, or read through transcripts which have been computer coded for further insights. Treating the two approaches as complementary undermines complaints that computer coding is mechanical. The software assists the management and retrieval of data, but does not replace the intuitive, interpretive aspects of analysis. If viewing the transcript on screen creates a psychological 'distance', then researchers can supplement on-screen work by reading printed transcripts and listening to audio recordings.

There was substantial agreement between our two analyses; the major discrepancy concerned respondents' attitudes to Tesco and Ocado. While the impression created by the first analysis was that there was a conclusive preference for Ocado, the second analysis balanced this by showing that most respondents used, and would continue to use Tesco. Although Tesco was associated with many generic disadvantages, a detailed analysis shows that this may be because most respondents used Tesco. Qualrus enabled us to qualify the overall impression, not 
by the superficial approach of counting comments, but because it allowed us to examine all 'Tesco' and 'Ocado' comments.

The second analysis was more comprehensive and rigorous, contributing a number of additional insights. Some of these details may have been in the verbal presentation, but not in the report or presentation slides. This highlights the danger of outline reports; findings are of little use if they are not available for future reference. However, it is possible that the ready availability of numeric data within the CAQDAS interface encourages a quasi-quantitative approach (Robson and Foster, 1993). This is reflected to some extent in our findings, in our use of terms such as 'most' and 'main'; but as Pike and Thompson (1995) point out, this is not illegitimate per se, rather, care should be taken so that numeric terms are used self-consciously and appropriately. The traditional debrief reports the overall consensus of attitudes revealed in the groups, but as qualitative research is not representative, minority views are also of interest, and could in fact reflect mainstream views among the larger population. Using Qualrus as a supplementary tool, we were able to mine the data for more detail and clearly identify and explore minority views. Deviant or negative cases (Silverman, 2001) can be particularly useful in the development of theory, because understanding the exceptions helps to refine hypotheses. In qualitative research, much of respondents' discourse may not be directly relevant to the research brief, but nevertheless may be of interest to the client either immediately or at a later date. Comprehensive computer coding means that all this data is accessible, and can be revisited.

Different analysts will provide different interpretations of the same transcripts, even when using the same coding method. The differences in the two analyses in 
our experiment may therefore be due to differences between the analysts, rather than due to the technology employed. However, the first analyst was very experienced relative to the second analyst, who had only received three hours training on Qualrus from the CAQDAS Networking Project at Surrey University. The superior experience of the first is therefore likely to have created bias that minimised, rather than exaggerated, the contribution of the CAQDAS coding.

The value of computer assisted coding as a complementary form of analysis will depend on the specific market research objective. In some projects there may be very specific research objectives, for example, testing research materials prior to quantitative research. The required turnaround time is often very tight, and the moderator may be asked to report the findings without waiting for transcriptions and comprehensive coding, saving time and expense. In these cases, computer coding may be seen by both client and researcher as superfluous. However, other qualitative research projects are more exploratory, perhaps aimed at exploring brand equity, generating new product ideas or understanding a new market. In such cases there may be no specific research questions, and everything said within the interview may be useful to the client. Here, computer coding is clearly more relevant.

The most important advantage of coding using Qualrus was unexpected. This research is part of a large research project by the eCommerce Consumer Research Unit. The Qualrus analysis has created a data bank that can be quickly and easily accessed by members of the team, providing detailed information on numerous aspects of grocery shopping usage and attitudes. This resource has already proved useful, both for writing this paper, and in assisting the design of the questionnaire for the second stage of the project. This has implications for marketing managers, 
because although particular research projects may have short-term objectives, over time companies conduct many qualitative studies on a specific brand or market. Use of CAQDAS would enable marketing companies to build up a longterm database that could be used to track changes, as suggested by Barker and Nancarrow (1999). However, market research clients show little interest in computer analysis (Robson and Hedges, 1993) and there is little enthusiasm among qualitative researchers. There may be a concern among qualitative researchers that the creation of a CAQDAS qualitative research database could ultimately reduce client reliance on their skills, but an alternative approach is to develop such a database within the research agency, creating a tangible asset and competitive advantage.

Our findings indicate that there is minimal usage of CAQDAS in commercial market research companies, but that it has considerable potential as a supplementary tool and long term resource. There is a need for further research experiments; ideally these would be long-term and within commercial environments.

\section{References}

Barker, A., and Nancarrow, C. (1999), "The shock of the new: The technological revolution in qualitative marketing research", ESOMAR Congress, Paris.

Becker, H. S., Gordon, A. C., and LeBailly, R. K. (1984), "Fieldwork with the computer", Qualitative Sociology, Vol. 7, No. 1/2, pp. 16-33.

Bezborodova, B. and Bennett, B. (2004), "An investigation into the non-usage of qualitative software in the marketing research industry", Irish Marketing Review, Vol. 17, No 1/2, pp. 1-5.

Bong, S. A. (2002), "Debunking myths in qualitative data analysis", Forum Qualitative Social Research, Vol. 3, No. 2, available at: http://www.qualitative-research.net/fqs/fqs-e/inhalt2-02-e.htm 
Catterall, M. and MacLaran, P. (1997), "Focus group data and qualitative analysis programs: Coding the moving picture as well as the snapshots", Sociological Research Online, Vol. 2, No. 1, available at: http://www.socresonline.org.uk/2/1/6.html

Catterall, M. and Maclaran, P. (1998), "Using Computer Software for the Analysis of Qualitative Market Research Data", International Journal of Market Research, Vol. 40, No. 3.

Coffey, A. and Atkinson, J. M. (1996), “Making Sense of Qualitative Data”, Sage Publications, London.

Coffey, A., Holbrook, B., and Atkinson, P. (1996), "Qualitative data analysis: Technologies and representations", Sociological Research Online, Vol. 1, No. 1, available at: http://www.socresonline.org.uk/socresonline/1/1/4.html

Conrad, P. and Shulamit, R. (1984), "Computers and qualitative data: an introduction”, Qualitative Sociology, Vol. 7, No. 1/2, pp. 3-15.

Dolan, A. and Ayland, C. (2001), “Analysis on trial”, International Journal of Market Research, Vol. 43, No. 4.

Ereaut, G., Imms, M., and Callingham, M. (2002), Analysis and Interpretation in Qualitative Market Research, Vol. 4, Qualitative Market Research: Principle and Practice, Sage, London.

Fielding, N. (1994), "Getting into computer-aided qualitative data analysis", Data Archive Bulletin, available at: http://caqdas.soc.surrey.ac.uk/fieldinggettinginto.pdf

Fielding, N. G. and Lee, R. M. (1998), Computer Analysis and Qualitative Research, Sage, London.

Gerson, E. (1984), "Qualitative research and the computer", Qualitative Sociology, Vol. 7, No. 1/2, pp. 61-67.

Gordon, W. and Langmaid, R. (1988), Qualitative Market Research: A Practitioner' and Buyer's Guide, Gower, London.

Gordon, W. (1999), Goodthinking: A Guide to Qualitative Research, Admap publications, Henley.

Huberman, A. M. and Miles, M. B. (1994), "Data management and analysis methods," in Handbook of Qualitative Research, N. K. Denzin and Y. S. Lincoln, Eds., pp. 428-444. 
Lee, M. and Fielding, N. (1996), "Qualitative data analysis: Representations of a technology: A comment on Coffey, Holbrook and Atkinson”, Sociological Research Online, Vol. 1, No. 4, available at: http://www.socresonline.org.uk/socresonline/1/1/4.html.

Lonkila, M. (1995), "Grounded theory as an emerging paradigm for computerassisted qualitative data analysis," in Computer-Aided Qualitative Data Analysis: Theory, Methods and Practice, U. Kelle, Ed., Sage Publications, London.

Mason, J. (1999) Qualitative Researching, Sage, London.

Maclaran, P. and Catterall, M. (2002), "Analysing qualitative data: computer software and the market research practitioner", Qualitative Market Research: An International Journal, Vol. 5, pp. 28-39.

Nancarrow, C., Moskin, A., and Shankar, A. (1996), "Bridging the great divide the transfer of techniques", Marketing Intelligence and Planning, Vol. 14, No. 6, pp. 27-37.

Padilla, R. (1991), "Using computers to develop conceptual models", Qualitative Sociology, Vol. 14, No. 3, pp. 263-274.

Pike, R., Thompson, L. (1995), "The technological fix in qualitative research let's be honest in what we are trying to achieve", Proceedings of ESOMAR Seminar: Looking through the Kaleidoscope: That Is the Qualitative Mission?, Paris.

Robson, S. and Hedges, A. (1993) "Analysis and interpretation of qualitative findings: Report of the MRS Qualitative Interest Group", Journal of the Market Research Society, Vol. 35, No. 1, pp. 23-35.

Roberts, K. A. and Wilson, R. W. (2002), "ICT and the research process: Issues around the compatibility of technology with qualitative data analysis", Forum Qualitative Social Research, Vol. 3, No. 2, available at: http://www.qualitative-research.net/fqs-texte/2-02/2-02robertswilsone.htm

Seidel, J. and Clark, J. (1984), "The Ethnograph: a computer programme for the analysis of qualitative data", Qualitative Sociology, Vol. 7, No. 1/2, pp. $110-125$.

Silverman, D. (2001), Interpreting Qualitative Data, Sage, London.

Tesch, R. "Comparing methods of qualitative analysis: What do they have in common?", in American Educational Research Association Annual Meeting, Washington. 
Thompson, R. (2002), "Reporting the results of computer-assisted analysis of qualitative research data", Forum Qualitative Social Research, Vol. 3, No. 2, available at: http://www.qualitative-research.net/fqs-texte/2-02/202thompson-e.htm

Verdict (2004), Etailing 2004, Verdict Research Limited, London. 
Figure 1 Experiment Protocol

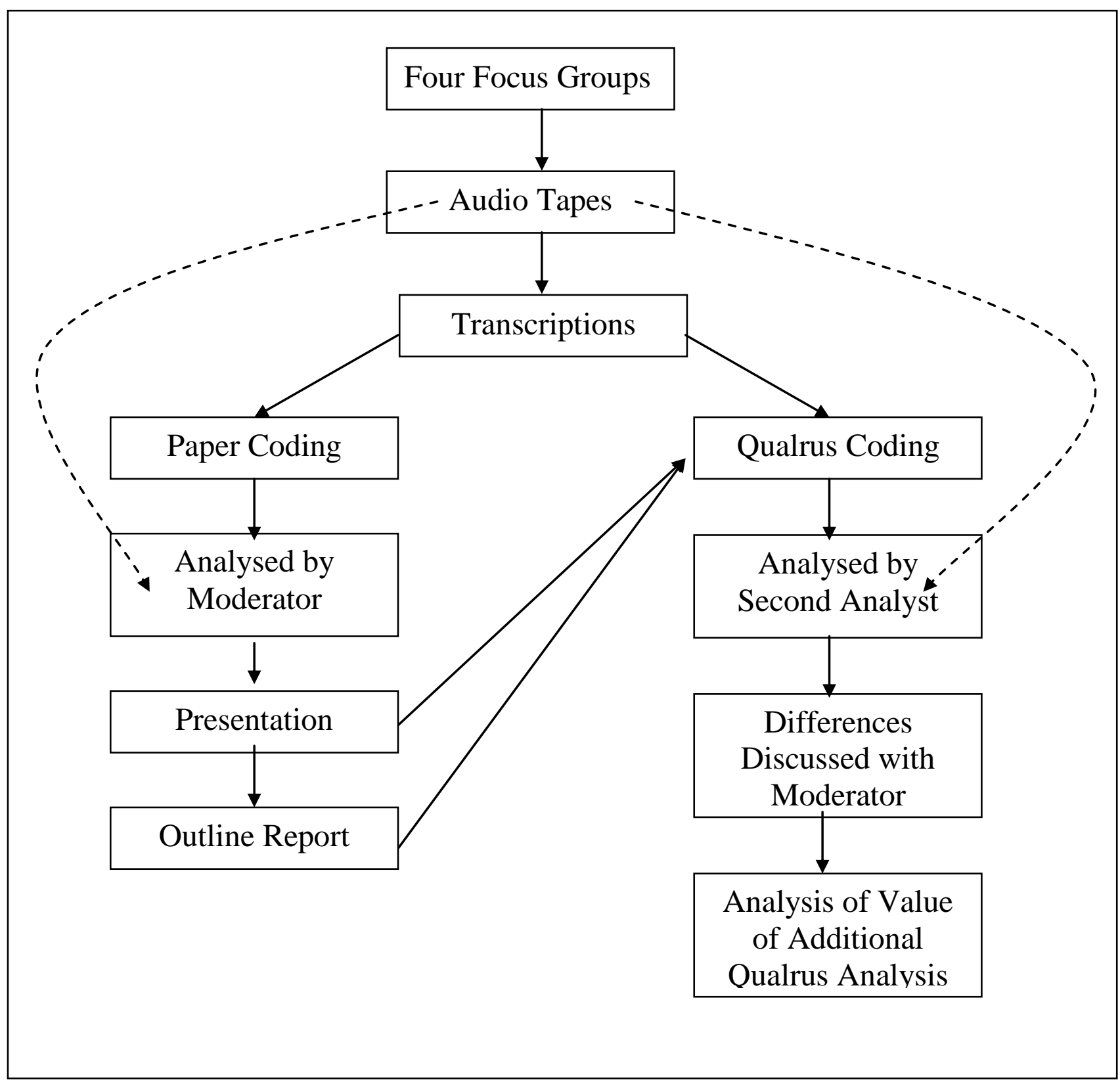


Figure 2. Qualrus Interface Showing Segments Coded 'Lifestyle Change'

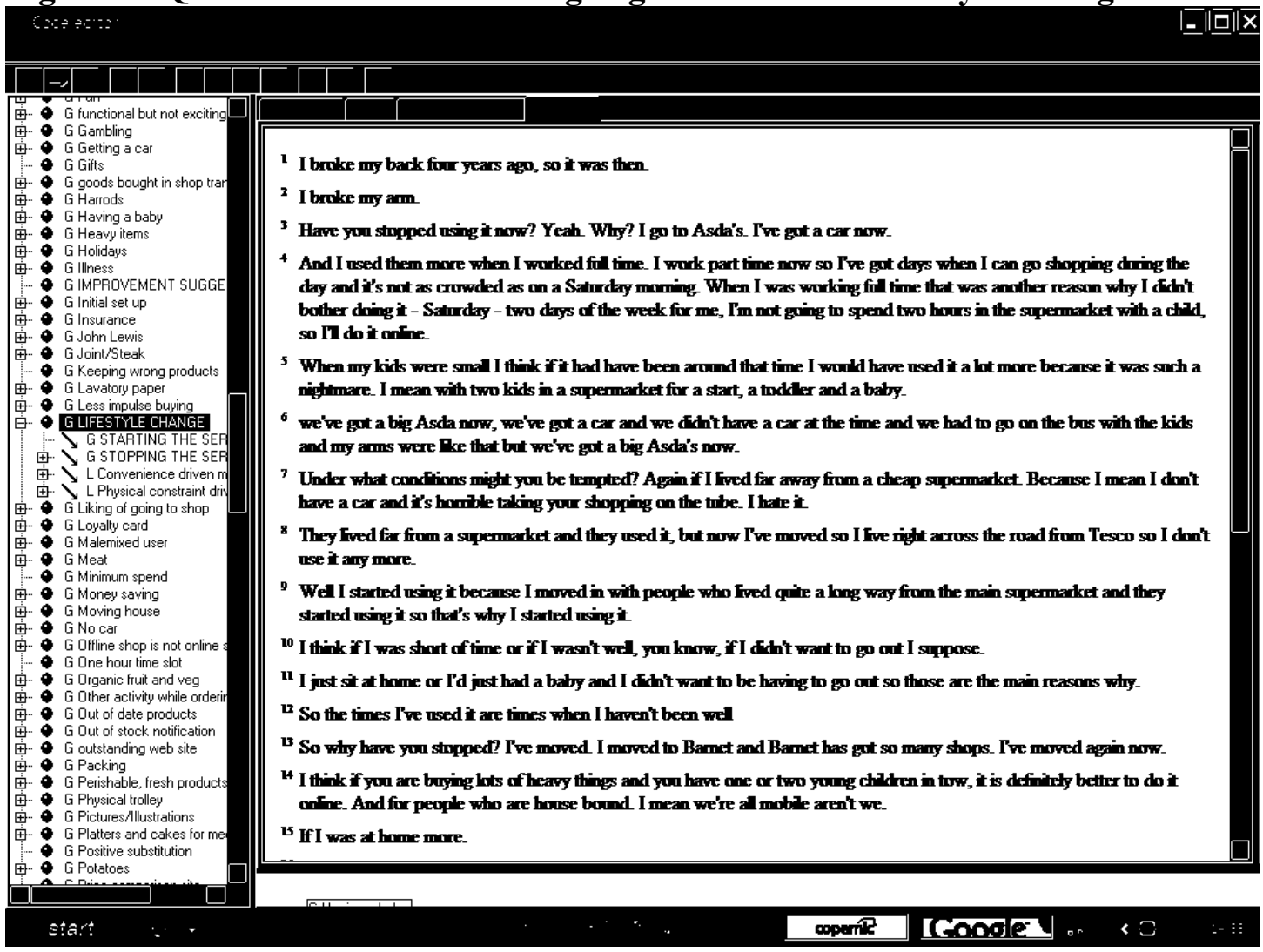


Table I Awareness and Usage of CAQDAS

\begin{tabular}{lcr}
\hline & Number of Respondents & $\%$ \\
\hline Not heard of & 38 & 25 \\
Heard of, not used & 86 & 56 \\
Tried, never used & 16 & 10 \\
Usually use & 13 & 9 \\
Total & 153 & 100 \\
\hline
\end{tabular}


Table II Brand Awareness of CAQDAS packages

\begin{tabular}{lcc}
\hline & No. of Respondents & \% of Respondents \\
\hline NUDIST & 39 & 34 \\
NVivo & 15 & 13 \\
QUALPRO & 14 & 12 \\
ATLAS-ti & 9 & 8 \\
Xsight & $9 *$ & $8^{*}$ \\
Ethnograph & 6 & 5 \\
Maxqda & 3 & 3 \\
Transana & 2 & 2 \\
Qualrus & 1 & - \\
None of these/ no answer & 56 & 48 \\
\hline
\end{tabular}

*Not listed in the questionnaire 